\title{
Expresión génica de BMPR1, BMPR2, y TGFBR1 en dentina humana tratados con diferentes soluciones desmineralizantes $y$ adhesión de las células de papila apical cultivada
}

\section{Gene expression of BMPR1, BMPR2, and TGFBR1 in human dentin treated with different demineralizing solutions and adhesion of cultured apical papilla cells}

\author{
Paola Daniela Hidalgo Araujo ${ }^{1}$, Ana Clara Fagundes Pedroni², Lais Prado \\ Cunha $^{3}$, Elaine Faga Iglecias ${ }^{4}$, Giulio Gavini ${ }^{5}$
}

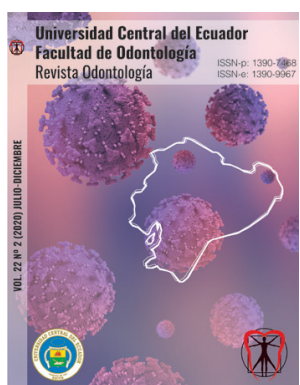

\author{
${ }^{1}$ Docente; Facultad de Odontología; Universidad Central \\ del Ecuador; Quito, Ecuador. \\ 凶phidalgo@uce.edu.ec \\ (D) https://orcid.org/0000-0002-8751-0753 \\ ${ }^{2}$ Facultad de Odontología de la Universidad de São \\ Paulo, São Paulo/ SP- Brasil. \\ (D) https://orcid.org/0000-0002-1391-3832 \\ ${ }^{3}$ Facultad de Odontología de la Universidad de São \\ Paulo, São Paulo/ SP- Brasil. \\ (D) https://orcid.org/0000-0002-7547-6973 \\ ${ }^{4}$ Facultad de Odontología de la Universidad de São \\ Paulo, São Paulo/ SP- Brasil. \\ (D) https://orcid.org/0000-0002-1350-3542 \\ ${ }^{5}$ Facultad de Odontología Campinas, São Paulo/ SP- \\ Brasil. \\ (D) https://orcid.org/0000-0002-3254-2504
}

*Autor de correspondencia: phidalgo@uce.edu.ec

\section{ODONTOLOGÍA}

https://revistadigital.uce.edu.ec/index.php/odontologia/index ISSN-e: 1390-9967

ISSN: $1390-7468$

Periodicidad: semestral

vol. 23, núm. 2, 2021

fod.revista@uce.edu.ec

DOI: https://doi.org/10.29166/odontologia.vol23.n2.2021-e3440

\section{Resumen}

El éxito de los procedimientos de endodoncia regenerativa depende de la descontaminación del espacio endodóntico, la presencia de células mesenquimales indiferenciadas, la liberación de factores de crecimiento que actúan como moléculas señalizadoras para la atracción, proliferación y diferenciación celular; y de la presencia de un "scaffold", que brinde soporte a la organización y vascularización del tejido recién formado. Objetivo. Analizar soluciones quelantes específicas de calcio EGTA, Ácido Cítrico y EDTA en la liberación de factores de crecimiento (BMPR1, BMPR2 y TGFBR1) presentes en la dentina como la adhesión célular. Materiales y Métodos. Se obtuvieron discos de dentina de premolares y terceros molares humanos, después de la imnersión por 1 minuto con EDTA, EGTA y Ácido Cítrico, se sembraron las células. La adhesión celular se evaluó a las 48 horas usando MEV. La expresión génica se determinó a los 7 y 21 días de cultivo celular. El análisis estadístico fue ANOVA seguido de Tukey, con un nivel de significancia del 5\%. Resultados. A los 21 días, el tratamiento con EGTA aumento significativamente BMPR1 en comparación con PBS. Ninguna condición experimental alteró la expresión de BMPR2. La expresión de TGBR1 a los 21 días aumentó significativamente al tratamiento con EGTA. Aunque no hubo una distribución uniforme de células a lo largo de los discos, se observó adhesión celular en todos los grupos experimentales. Conclusiones. El tipo de solución desmineralizante interfiere con la cantidad liberada de factores de crecimiento BMPR1 y TGFBR1, de la dentina humana, y no interfiere en la adhesión celular.

Palabras Clave: Diferenciación Celular, Adhesión Celular, EGTA, Endodoncia Regenerativa, Células Madre.

\section{Abstract}

The success of regenerative endodontic procedures depends on the decontamination of the endodontic space, the presence of undifferentiated mesenchymal cells, the release of growth factors that act as signaling molecules for cell attraction, proliferation and differentiation; and the presence of a "scaffold" that supports the organization and vascularization of the newly formed tissue. Objetive. Analyze specific chelating solutions of calcium EGTA, Citric Acid and EDTA in the release of growth factors (BMPR1, BMPR2 and TGFBR1) present in dentin as cell adhesion. Materials and Methods. Dentin discs were obtained from human premolars and third molars, after immersion for 1 minute with EDTA, EGTA and Citric Acid, the cells were seeded. Cell adhesion was assessed at 48 hours using MEV. Gene expression was determined at 7 and 21 days of cell culture. The statistical analysis was ANOVA followed by Tukey, with a significance level of 5\%. Results. At 21 days, EGTA treatment significantly increased BMPR1 compared to PBS. No experimental conditions altered the expression of BMPR2. TGBR1 expression at 21 days increased significantly to EGTA treatment. Although there was not a uniform distribution of cells throughout the discs, cell adhesion was observed in all experimental groups. Conclusions. The type of demineralizing solution interferes with the amount of growth factors BMPR 1 and TGFBR1 released from human dentin and does not interfere with cell adhesion.

Keywords: Cell Differentiation, Cell Adhesion, EGTA, Regenerative Endodontics, Stem Cells. 


\section{Introducción}

En dientes con formación radicular incompleta, la necrosis pulpar resulta en la parálisis del proceso de rizogénesis, dando como resultado dientes con ápices abiertos, conductos anchos y paredes radiculares delgadas y frágiles. El tratamiento de endodoncia, en estos casos, la apexificación, tiene como objetivo promover la formación de una barrera apical que permita el posterior llenado del conducto radicular, sin extravasación del material de obturación ${ }^{1}$. Ahora bien, independientemente del tipo de medicamento utilizado, ya sea hidróxido de calcio o MTA, existe riesgo de fractura radicular y no fortalece ni permite el desarrollo continuo de las raíces, manteniendo la debilidad de las paredes dentinarias ${ }^{2-5}$. A partir del año 2000 surge la terapia endodóntica regenerativa como alternativa a la apexificación para el tratamiento de dientes no vitales, que emplea dos conceptos: regeneración tisular e invaginación de células mesenquimales indiferenciadas ${ }^{6}$. La regeneración pulpar estudia el desarrollo de nuevo tejido pulpar in vitro a partir de células indiferenciadas estimuladas por factores de crecimiento, con el objetivo de regenerar el tejido pulpar perdido ${ }^{7,6}$. Ahora invaginación de células indiferenciadas de la región apical de los dientes en pacientes jóvenes con ápice abierto ${ }^{7}$, se basa en la supervivencia de estas células a la necrosis pulpar, incluso en presencia de infección perirradicular ${ }^{8}$. Wang y cols ${ }^{5}$ evaluaron mediante análisis histológico el tipo de tejido formado después de procedimientos de endodoncia regenerativa en perros y concluyeron que el espacio pulpar está formado por tejido duro similar al cemento, también observado por Gomes-Filho y cols ${ }^{9}$. Para el éxito de los procedimientos de endodoncia regenerativa es fundamental la presencia de la tríada: células madre, andamios que dan soporte a la organización celular, proliferación, diferenciación y vascularización y factores de crecimiento que actúan como moléculas señalizadoras $^{10}$. Wingler y cols ${ }^{11}$ afirman que es fundamental eliminar el tejido pulpar necrótico acompañado de la desinfección química del conducto radicular, y la instrumentación está contraindicada. El hipoclorito de sodio es la sustancia más utilizada en todo el mundo ${ }^{12}$ y tiene propiedades antimicrobianas contra los principales patógenos endodónticos, pudiendo utilizarse en diversas concentraciones de cloro libre ${ }^{13}$. Treviño y cols ${ }^{14}$ demostraron que el uso de $\mathrm{NaOCl}$ no afecta la supervivencia de las células mesenquimales indiferenciadas, a diferencia de la Clorhexidina (CHX), que quizás por su sustantividad, parece interferir con la adhesión de estas células. Además del uso de soluciones antimicrobianas, también es necesario usar agentes desmineralizantes para eliminar la capa de frotis, siendo los más comunes el ácido etilendiaminotetraacético (EDTA), el ácido cítrico y MTAD ${ }^{\circledR}$. El EDTA es capaz de liberar varios factores de crecimiento presentes en la matriz dentinaria ${ }^{15,16}$, por lo que su uso está indicado por la Asociación Americana de Endodoncia ${ }^{10}$. El EDTA es un compuesto orgánico que actúa como agente quelante, formando complejos muy estables con varios iones metálicos, acción que es autolimitante debido al cambio de $\mathrm{pH}$ durante el proceso de desmineralización de la dentina hasta la saturación de la solución ${ }^{13}$. EDTA al libera factores de crecimiento que pueden facilitar la adhesión de células mesenquimales indiferenciadas e inducir su diferenciación en odontoblastos y osteoblastos ${ }^{17}$. Factores de crecimiento, incluido el factor de crecimiento de fibroblastos 1 y 2 (FGF-1, FGF-2), el factor de crecimiento transformante 1 (TGF-1), la proteína osteomorfogenética 2 (BMP-2), el factor de crecimiento derivado de plaquetas (PDGF) y factor de crecimiento epidérmico (EGF), así como factores angiogénicos como el factor-factor de crecimiento endotelial vascular (VEGF), que regulan las respuestas inmunes, angiogénicas, de reclutamiento celular, proliferación y diferenciación, que servirán como guía celular en protocolos dirigidos a tejidos regeneración ${ }^{18}$. El sistema TGF- $\beta$ regula una variedad de procesos biológicos, incluida la morfogénesis, el desarrollo embrionario, la reparación de tejidos y la inflamación ${ }^{19}$. Cassidy y cols. ${ }^{20}$ detectaron isoformas de TGF- $\beta$ en el contenido orgánico e inorgánico de la dentina, predominando el TGF- $\beta 1$. Los receptores de tipo I y II para TGF- $\beta$ fueron informados en células pulpares por Toyono y cols ${ }^{21}$, que sugiere fuertemente la funcionalidad de este factor de crecimiento en el tejido pulpar.

Estos autores también correlacionan la expresión de TGF- $\beta 1$ durante la fase de síntesis de proteínas por células de tipo odontoblastos. La aplicación de TGF- $\beta 1$ y TGF- $\beta 3$ al tejido pulpar de ratas cultivadas indujo la producción de dentina restauradora ${ }^{22}$. De hecho, TGF- $\beta 1$ condujo a una mayor síntesis de ADN por las células pulpares in vitro, lo que sugiere su potencial inductor de la proliferación ${ }^{23}$. Shiba y cols. ${ }^{24}$ demostraron un mayor contenido de proteínas, producción de fibronectina e inducción de la proliferación. Este último fenómeno inducido por TGF- $\beta 1$ también fue demostrado por Melin y $\operatorname{cols}^{25}$, en cultivo de tejido de pulpa dental humana. Las BMP's constituyen la subfamilia más grande de la superfamilia TGF- $\beta^{26}$, con la excepción de la proteína BMP-1, que participa en el proceso de lisis de las fibras de colágeno maduras y cuya estructura no se asemeja a la de la familia de TGF- $\beta^{27-29}$. Pero actualmente Ivica y cols.(30), muestra la liberación de TGF- $\beta 1$ de premolares humanos maduros e inmaduros depositados en dentina peritubular. 
Galler y cols ${ }^{31}$, señalan que el acondicionamiento de la dentina favorece la migración celular, ya que, al promover la liberación de factores de crecimiento, estos pueden difundirse a la sangre del conducto radicular, estableciendo un gradiente que promueve la migración celular dentro del conducto y la adhesión a las paredes de la dentina. Además, los factores de crecimiento expuestos en la dentina favorecen la diferenciación de las células adheridas. Hashimoto y $\operatorname{cols}^{32}$, concluyeron que la irrigación final con EDTA durante 10 minutos de discos de dentina bovina pretratados con $1,5 \%$ de $\mathrm{NaOCl}$ aumenta la adhesión y diferenciación celular, ya que además de eliminar la capa de frotis y exponer factores de crecimiento, también expone componentes de la matriz, como los tipos de colágeno. I, III y V, o glicosaminoglicanos, con posterior activación de la señalización de la integrina / PI3K, fundamentales para la recuperación de la superficie dentinaria, alterada por el pretratamiento con $\mathrm{NaOCl}$. Una mayor adhesión celular está relacionada con el aumento de la humectabilidad de la superficie provocada por el uso de EDTA. El efecto quelante del EDTA depende de factores como pH, temperatura, concentración, presentación y sus asociaciones, además del tiempo de contacto, destacando que el tiempo óptimo de desmineralización es de 15 minutos $^{33-35}$. Calt y $\operatorname{Serper}^{36}$ informan que el EDTA quela los iones $\mathrm{Ca}+$ así como otros cationes divalentes, desmineraliza la dentina y elimina los componentes inorgánicos de la capa de frotis. EGTA se une más específicamente a los iones de calcio y comparó la eliminación de la capa de frotis entre EDTA al 17\% y EGTA al 17\% y los dos posteriormente se regaron con $\mathrm{NaOCl}$ al 5\% y mostraron que el EDTA lo eliminó por completo causando erosión, y el EGTA también eliminó la capa de frotis sin causar erosión. Otro desmineralizador utilizado en Endodoncia es el ácido cítrico, que es un ácido orgánico débil que tiene propiedades descalcificantes similares al EDTA, siendo menos citotóxico ${ }^{37-39}$. Dado lo anterior, es evidente que el tratamiento superficial de la dentina intracanal con soluciones irrigantes con capacidad desmineralizante puede interferir positivamente en la adhesión y diferenciación celular, jugando un papel importante en los procedimientos de endodoncia regenerativa. Encontrar la solución desmineralizante más eficaz, menos citotóxica, que promueva una mayor humectabilidad de la superficie dentinaria, sin provocar su erosión, liberando los factores de crecimiento presentes en la matriz orgánica, es de suma importancia para el éxito de la regeneración pulpar.

\section{Materiales y métodos}

\section{Cultivo celular}

El proyecto se llevó a cabo después de la aprobación del Comité de Ética de la Facultad de Odontología de la Universidad de São Paulo (Dictamen No. 2.253.947, CAAE: 73429617.0.0000.0075).

Se utilizaron células del linaje SCAP (células tronco de la papila apical) previamente caracterizadas, las cuales fueron criopreservadas en el biodepósito celular del Laboratorio de Investigación Básica del Departamento de Odontología de la Facultad de Odontología de la Universidad de São Paulo.

\section{Descongelación y expansión celular}

Para el descongelamiento y cultivo de las células de la papila apical, se utilizó medio de Eagle modificado $\alpha$ (Gibco, Invitrogen, Life Technologies, Carlsbad, CA, EE. UU.), Suplementado con 15\% de suero fetal bovino (FBS) (Gibco), 2 mM L- glutamina (Invitrogen, Life Technologies, Carlsbad, EE. UU.), Lascorbate-2-fosfato $100 \mu \mathrm{M}$ (Sigma-Aldrich, St. Louis, EE. UU.), Penicilina $100 \mathrm{U} / \mathrm{ml}$ y estreptomicina $100 \mu \mathrm{g} / \mathrm{ml}$ (Invitrogen). Los frascos de cultivo se mantuvieron en incubadora a $37 \mathrm{oC}$ con $5 \%$ de $\mathrm{CO} 2$ y $100 \%$ de humedad hasta que las células alcanzaron el 70\% del área cultivable, con cambios de medio cada 2-3 días. La expansión celular se realizó donde la capa celular se lavó con PBS (1X, tampón salino-fosfato $\mathrm{pH}=7,2$; LGC Biotechnology) y se utilizó una solución de tripsina al 0,25\% (1 ml) que contenía ácido etilendiaminotetraacético para la eliminación (EDTA) $1 \mathrm{mM}$ (Invitrogen / Gibco), durante 3 minutos a 37oC. La tripsina se inactivó con medio de cultivo que contenía PBS y las células en suspensión se centrifugaron a 800 x g / 5 min / TA. Se mantuvieron nuevamente alícuotas de esta suspensión celular en un horno a 37oC con 5\% de CO2 y 100\% de humedad. El uso de células se produjo a partir del cuarto pase en adelante.

\section{Preparación de discos de dentina}

Los premolares y terceros molares humanos sanos se obtuvieron de Biobanco fa FOUSP - División de dientes humanos y se almacenaron en una solución de cloramida al 0,5\%.

Se extrajo la corona (Isomet; Buehler Ltd, Evanston, IL) y se seccionó la raíz longitudinalmente en dos mitades. De la superficie interna de cada raíz se obtuvieron discos de $4 \mathrm{~mm}$ de ancho, obtenidos con la ayuda 
de una trépano de $4 \mathrm{~mm}$ y $1 \mathrm{~mm}$ de espesor. Fueron pulidos en papel de lija de peso decreciente (600-, 800-, 1000- y 2000). Las muestras se mantuvieron en EDTA al 17\% durante 1 min en un baño ultrasónico para eliminar la capa de frotis y se enjuagaron en PBS durante 1 min.

Para imitar el protocolo de revascularización, los discos se irrigaron con $100 \mu 1$ de NaOCL al 1,5\% durante $1 \mathrm{~min}$. Los discos de dentina se lavaron con $200 \mu 1$ de PBS y se dividieron en 4 grupos experimentales: PBS (control negativo), EDTA al 17\%, EGTA al 17\% y ácido cítrico al 15\%. Las muestras se sumergieron en $100 \mu 1$ de solución y se incubaron durante 1 minuto a temperatura ambiente. Luego, las muestras se retiraron y se colocaron individualmente en pocillos de placas de 96 pocillos que contenían $100 \mu$ le $\alpha$-MEM 15\% FBS.

\section{Ensayo de adhesión celular}

Las células se separaron de los matraces, se centrifugaron a $800 \mathrm{x} \mathrm{g} / 5 \mathrm{~min} / \mathrm{RT}$ y se contaron ajustadas a una concentración de $8 \times 104$ células / mL y se distribuyeron en cada pocillo en un volumen de $100 \mu \mathrm{L}$, totalizando $8 \times 103$ células / pocillo. Después de $4 \mathrm{~h}$ para permitir la adhesión, se añadieron $100 \mu 1$ de medio completo por un total de $200 \mu 1$.

Las células se cultivaron durante 48 horas para el análisis SEM de la adhesión en los discos y durante 7 y 21 días para la extracción de ARN.

\section{Extracción de ARN para la expresión génica de BMPR1, BMPR2 y TGFBR1 a partir de células papila- res apicales}

La expresión génica de BMPR1, BMPR2 y TGFBR1 de las células de la papila apical se evaluó mediante transcripción inversa seguida de reacción cuantitativa en cadena de la polimerasa (RT-qPCR) en muestras recolectadas a los 7 y 21 días después de cada uno de los 4 tratamientos propuestos (PBS, EDTA, Citric ácido y EGTA) en los discos de dentina.

El ARN total (ARN) se obtuvo homogeneizando las muestras en Trizol [isotiocianato de guanidina

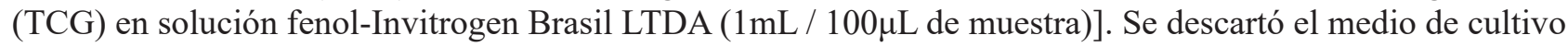
de cada muestra y luego se agregaron $100 \mu \mathrm{L}$ de Trizol. La solución se transfirió a tubos de microcentrífuga donde se agregaron $900 \mathrm{~L}$ de Trizol, totalizando $1000 \mu \mathrm{L}$ según lo recomendado por el fabricante. En los pocillos que contenían discos, estos se transfirieron a tubos y se agitaron vigorosamente con vórtex. Las muestras se almacenaron a -80 o $\mathrm{C}$.

Antes de la extracción de ARN, los discos de dentina se desecharon con la ayuda de unas pinzas. Se agregaron $300 \mathrm{~mL}$ de cloroformo y luego de agitar vigorosamente durante $15 \mathrm{~s}$, las muestras se centrifugaron a $13000 \mathrm{~g} / 15 \mathrm{~min} / 4 \mathrm{oC}$ (Eppendorf Centrifuge $5417 \mathrm{R}$ - Eppendorf, California, EE. UU.). La fase acuosa sobrenadante $(\sim 300 \mu \mathrm{L})$ se recuperó en un tubo nuevo y se le añadió $600 \mu \mathrm{L}$ de isopropanol. A esto le siguió otra centrifugación a $13000 \mathrm{~g} / 10 \mathrm{~min} / 4 \mathrm{oC}$ y se descartó la solución. El sedimento se lavó dos veces con $1 \mathrm{ml}$ de una solución de alcohol al 75\% en agua más dietilpirocarburo (DEPC) al 0,01\%, seguido de centrifugación a $7000 \mathrm{~g} / 5 \mathrm{~min} / 4 \mathrm{oC}$. Después de secar, el ARN se reconstituyó con agua DEPC al 0,01\% (12 $\mu 1)$.

\section{Cuantificación de ARNt}

Para estandarizar la cantidad de ARN antes de la transcripción inversa, se cuantificó el ARN total. Se analizaron alícuotas de $2 \mathrm{uL}$ por absorbancia a $260 \mathrm{~nm}$ y $280 \mathrm{~nm}$ en un espectrofotómetro (Synergy HT, Biotek, Winooski, EE. UU.), Y se calcularon las concentraciones de ARN considerando la relación $1 \mathrm{AU}=40 \mu \mathrm{g} / \mathrm{mL}$, según la fórmula:

$[\mathrm{ARN} \mu \mathrm{g} / \mathrm{mL}]=$ Abs X Factor de dilución X 40

Esas relaciones 260RNA / 280PROT entre 1.8 y 2.0 se consideraron adecuadas.

\section{Tratamiento con ADNasa}

Para el tratamiento con DNAsa (Sigma) se adicionó $1 \mu \mathrm{L}$ de Tampón $10 \mathrm{X}, 8 \mu \mathrm{L}$ de RNA + DEPC y $1 \mu \mathrm{L}$ de DNAsa I - Invitrogen Brasil LTDA), con un volumen final de 10 $\mu \mathrm{L}$. Luego, las muestras se incubaron a 37oC durante $30 \mathrm{~min}$. Posteriormente, se añadió $1 \mu \mathrm{L}$ de solución de parada ( $25 \mu \mathrm{M}$ EDTA) y luego esta solución se incubó a $65 \mathrm{o}$ C durante $10 \mathrm{~min}$. 


\section{Transcripción inversa}

Para la preparación de la hebra de ADN complementario (cDNA) (kit High Capacity RNA to cDNA) se utilizó en el producto de la reacción de RNA anterior tratado con DNAsa, de acuerdo con las recomendaciones del fabricante. La mezcla se preparó en tubos de microcentrífuga que contenían $10 \mu \mathrm{l}$ de tampón RT, $1 \mu 1$ de mezcla enzimática y $9 \mu \mathrm{l}$ de ARN total $+\mathrm{H} 2 \mathrm{O}$, totalizando $20 \mu \mathrm{l}$. La mezcla se incubó a $37^{\circ} \mathrm{C}$ durante 60 min y $95^{\circ} \mathrm{C}$ durante $5 \mathrm{~min}$, las muestras se almacenaron a $4^{\circ} \mathrm{C}$.

\section{Reacción en cadena de la polimerasa en tiempo real}

Las reacciones de qPCR se realizaron en un volumen final de $10 \mu \mathrm{L}$ conteniendo $1 \mu \mathrm{L}$ de cDNA (previamente transcrito), $0.5 \mu \mathrm{L}$ del oligonucleótido, $3.5 \mu \mathrm{L}$ de $\mathrm{H} 2 \mathrm{O}$ ultrapura y finalmente $5 \mu \mathrm{L}$ de Taqman Universal Mastermix (Thermofisher).

Los oligonucleótidos para TGFBR1, BMPRIA, BMPRIA2, GAPDH utilizados se adquirieron comercialmente (ensayos Taqman - Thermofisher). Las referencias son: TGFBR1 (Hs00610320_m1), BMPRIA (Hs01034913_g1), BMPRIA2 Hs00176148_m1) normalizado según la expresión génica de GAPDH (Hs02758991_g1).

Las reacciones de qPCR se realizaron por triplicado en placas de 96 pocillos en las siguientes condiciones: $95 \mathrm{oC}$ durante $10 \mathrm{~min}, 40$ ciclos de $95 \mathrm{oC}$ durante 15 sy $60 \mathrm{oC}$ durante $2 \mathrm{~min}$. Todas las reacciones se realizaron y analizaron utilizando el equipo ABI PRISM 7000 (Applied Biosystems). Se determinó el primer punto por debajo del límite fijo del producto de PCR (umbral de ciclo, Ct) para cada muestra. Los cambios en la expresión del gen diana se calcularon usando $2-\Lambda \Lambda \mathrm{Ct}$, en el que el $\mathrm{Ct}$ de la muestra experimental (gen diana $\mathrm{Ct}$-Ct GAPDH) se restó del Ct de la muestra de control (gen diana Ct-GAPDH).

\section{Preparación de muestras para análisis en Microscopía Electrónica de Barrido (SEM)}

Los discos de dentina se retiraron de los pocillos y se fijaron con paraformaldehído al $4 \%$ durante 30 min y se deshidrataron utilizando diluciones seriadas de etanol $(30 \%, 50 \%, 70 \%, 80 \%, 90 \%$ y 100\% durante 10 min cada una). Posteriormente, las muestras se secaron y se cubrieron con oro. La adhesión celular se observó usando SEM (1000x) (Kitikuson, Srisuwan, 2016).

\section{Análisis estadístico}

El análisis estadístico de la expresión génica se realizó utilizando el programa GraphPad Prism 7.0. Las diferencias estadísticamente significativas se determinaron mediante el análisis de varianza unidireccional (ANOVA) seguido de la prueba de Tukey para comparaciones entre las soluciones desmineralizantes probadas. Se adoptó un nivel de significancia del 5\% para verificar posibles diferencias entre los grupos experimentales.

El análisis de la adhesión de las células de la papila dental a los discos de dentina fue solo visual.

\section{Resultados}

A los 7 días, la expresión de BMPR1 no fue estadísticamente significativa entre las muestras, aunque muestra una tendencia creciente para el ácido cítrico (Figura 1A). A los 21 días, hay una reducción en la expresión de este receptor en el grupo donde los discos de dentina fueron tratados con PBS (Figura 1B). El tratamiento de la dentina con EGTA dio como resultado un aumento significativo del receptor en comparación con PBS.

Con respecto a la expresión de BMPR2, ninguna condición experimental indujo cambios en la expresión del gen del receptor para ambos períodos experimentales (Figura 5.1 C y D).

En 7 días, la expresión de TGBR1 no mostró cambios estadísticamente significativos (Figura 5.1 E). A los 21 días, hay una reducción significativa en la expresión del receptor en las muestras de dentina tratadas con PBS en comparación con MP y MD. Entre los grupos de dentina tratados, EGTA fue el único capaz de inducir un aumento significativo en la expresión del receptor TGBR1 (Figura 5.1 F). 

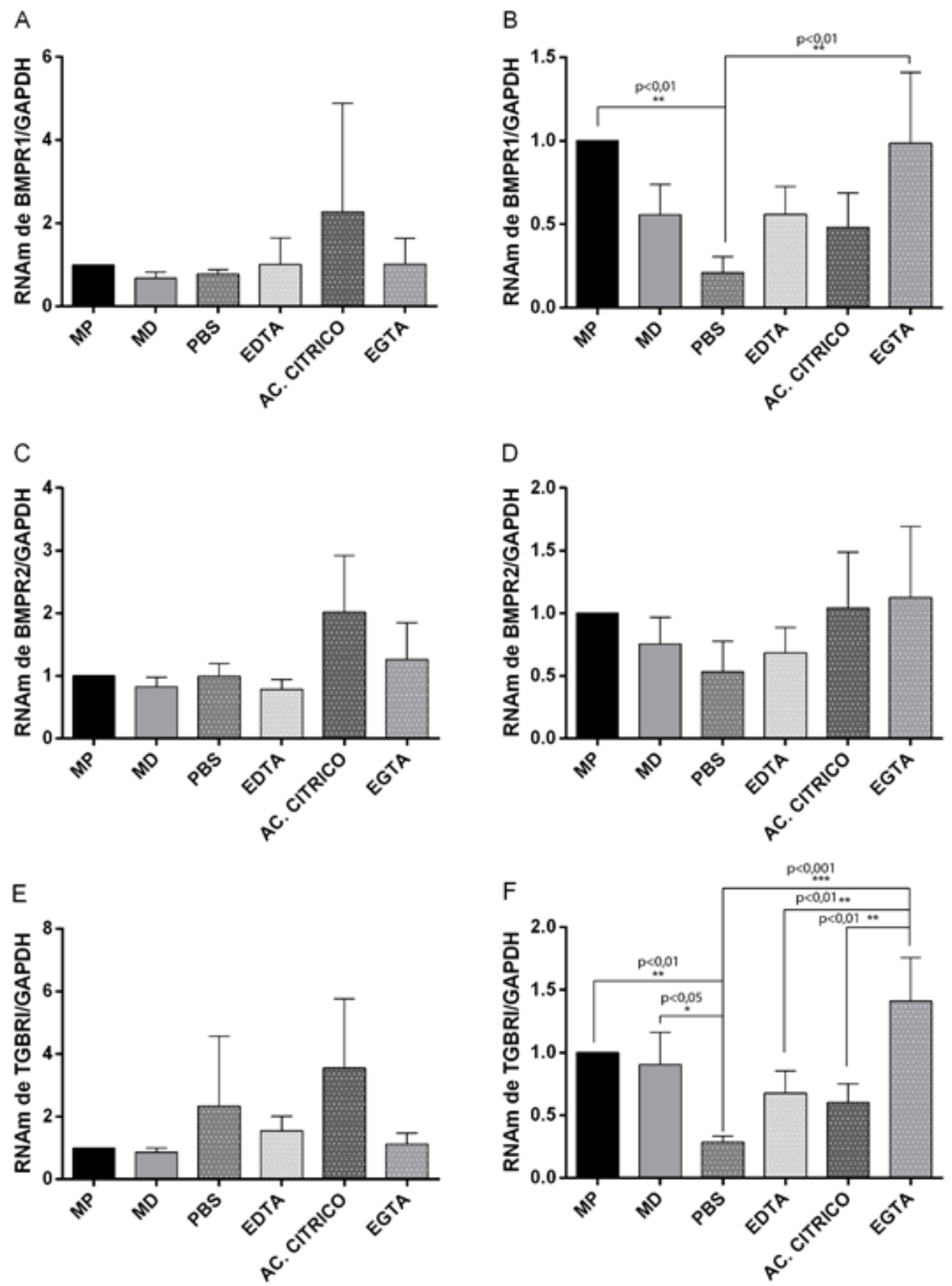

Gráfico 1. Expresión genética relativa de receptores para BMPR1 (1A - 7 días; 1B - 21 días), BMPR2 (1C 7 días; 1D - 21 días), TGFBR1 (1E - 7 días; 1F - 21 días). Los datos se obtuvieron por triplicado y representan la media y la desviación estándar de cada receptor en los diferentes tiempos experimentales.

Graph 1. Relative gene expression of receptors for BMPR1 (1A - 7 days; $1 B-21$ days), BMPR2 (1C - 7 days; $1 D$ - 21 days), TGFBRI (1E - 7 days; $1 F-21$ days). The data were obtained in triplicate and represent the mean and standard deviation of each receptor at the different experimental times. 


\section{Adhesión celular bajo microscopía electrónica de barrido}

Se observó adhesión celular en todos los grupos experimentales, aunque no hubo una distribución uniforme de las células a lo largo de los discos. El pequeño número de células observado en las microfotografías no permitió realizar el análisis estadístico.

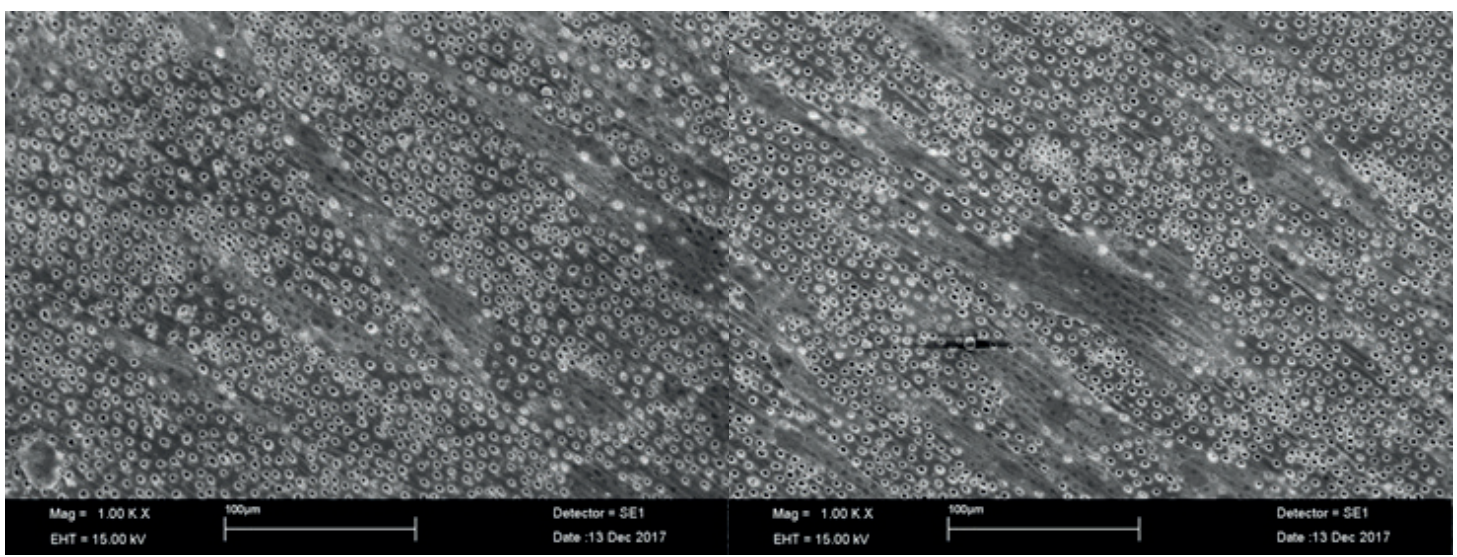

Figura 1. Fotomicrografias ilustrativas de la adherencia de las células de la papila apical en los discos de dentina tratados com PBS. (1000 x)

Figure 1. Illustrative photomicrographs of the adhesion of apical papilla cells to dentin discs treated with PBS. $(1000 x)$

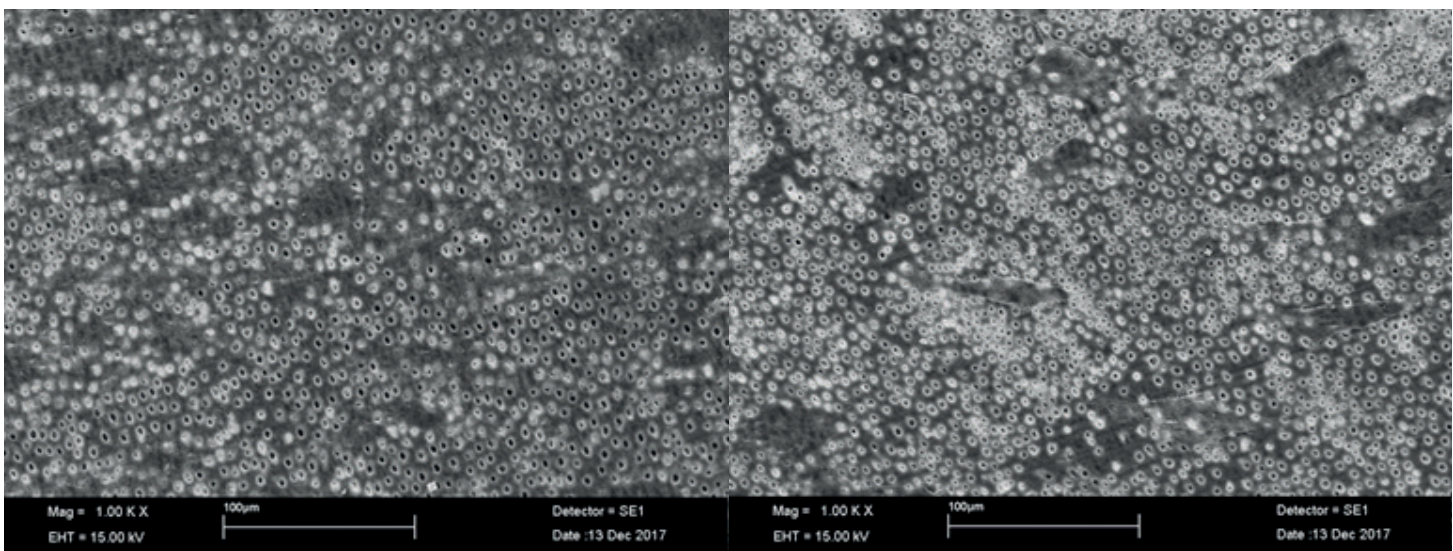

Figura 2. Fotomicrografias ilustrativas de la adherencia de las células de la papila apical en los discos de dentina tratados com EDTA 17\% (1000 x)

Figure 2. Illustrative photomicrographs of the adhesion of apical papilla cells to dentin discs treated with $17 \% \operatorname{EDTA}(1000 x)$

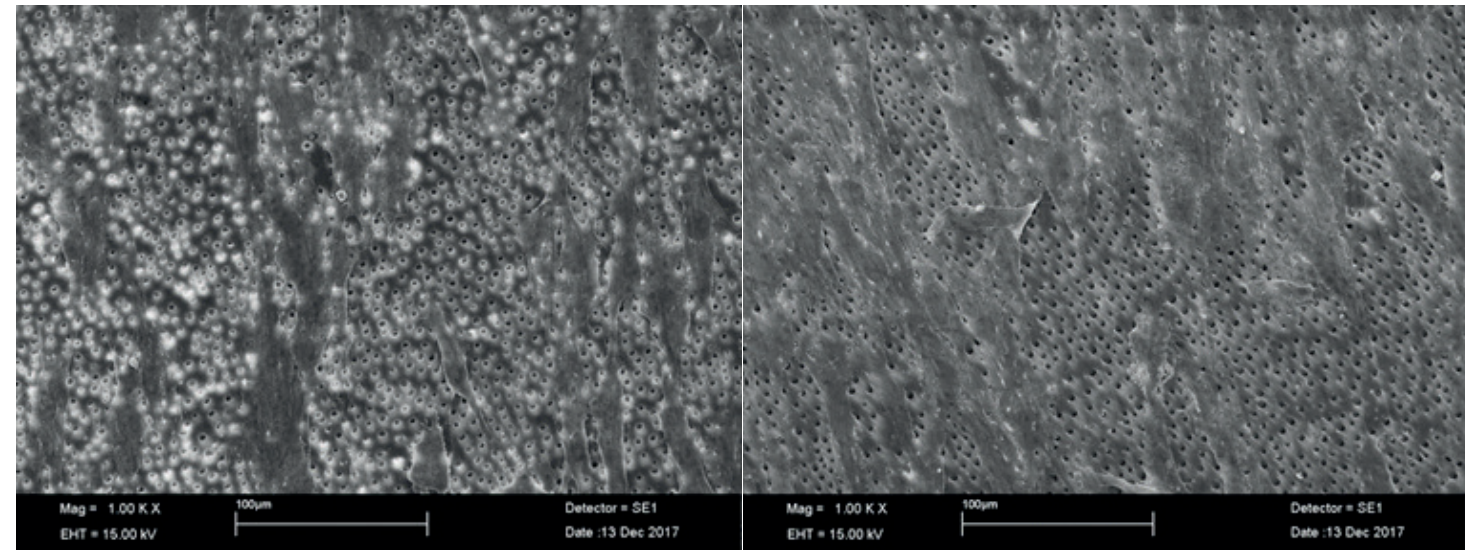

Figura 3. Fotomicrografias ilustrativas de la adherencia de las células de la papila apical en los discos de dentina tratados com Ácido cítrico 15\% (1000 x)

Figure 3. Illustrative photomicrographs of the adhesion of apical papilla cells to dentin discs treated with Citric Acid 15\% (1000 x) 


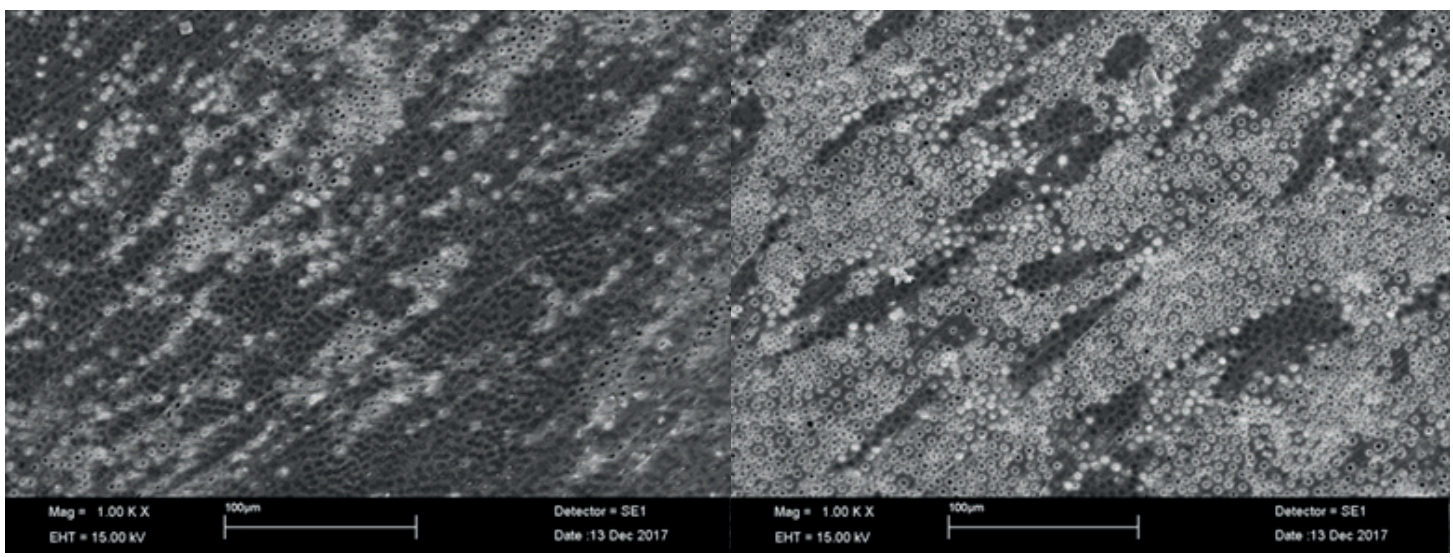

Figura 4. Fotomicrografias ilustrativas de la adherencia de las células de la papila apical en los discos de dentina tratados com EGTA 17\% (1000 x)

Figure 3. Illustrative photomicrographs of the adhesion of apical papilla cells to dentin discs treated with EGTA $17 \%(1000 x)$

\section{Discusión}

El análisis de la expresión de los genes BMPR1, BMPR2 y TGFBR1 resulta de los discos de dentina previamente tratados con EDTA, EGTA y ácido cítrico muestra que la solución desmineralizante puede interferir con la liberación de estos factores de crecimiento.

Los resultados de este estudio concuerdan con los obtenidos por Zhao y cols. ${ }^{16}$ quienes, al estudiar la liberación y localización ultraestructural de TGF- $\beta 1$, observaron que el tratamiento de la dentina con EDTA al $17 \%$ proporcionó una buena exposición de este factor de crecimiento en la superficie dentinaria, mientras que Ácido Cítrico al 10\% e Hipoclorito de Sodio a $3 \%$ liberó cantidades significativamente menores. Los autores enfatizan que la diferencia entre los efectos del EDTA y el ácido cítrico sugiere que la liberación de TGF- $\beta 1$ no solo ocurre debido al efecto desmineralizante de las soluciones, sino que podría estar relacionado con la capacidad del EDTA para solubilizar componentes de la sustancia orgánica. matriz de dentina ${ }^{40}$, además, este ácido no desmineraliza en profundidad la fibra de colágeno y solo disuelve el calcio extrafibrilar respetando el intrafibrilar ${ }^{41}$. Entre las soluciones probadas, EGTA a los 21 días indujo una mayor expresión de los receptores BMPR1 y TGBR1. La mayor especificidad de EGTA en el quelato de calcio puede explicar los resultados encontrados en este estudio.

En casos de revascularización pulpar de dientes con necrosis y rizogénesis incompleta, las células mesenquimales indiferenciadas tienen la capacidad de diferenciarse en odontoblastos, produciendo proteínas de la matriz dentinaria. Estos procesos están modulados por varios factores de crecimiento ${ }^{20,42}$ que son capaces de regular el comportamiento de las células pulpares. La reparación de la pulpa es un fenómeno complejo, ya que muchos de estos factores están involucrados como el factor de crecimiento transformante (TGF- $\beta$ ), las proteínas morfogenéticas óseas (BMP), el factor de crecimiento de la insulina (IGF), el factor de crecimiento de fibroblastos (FGF) y el derivado de plaquetas. Factor de crecimiento (PDGF) ${ }^{43}$. EGTA incluso mostrando un aumento en la liberación de TGB posiblemente podría ayudar a desarrollar el proceso de regeneración de manera más efectiva. En el proceso de regeneración, es fundamental que se produzca la adhesión celular, de modo que pueda producirse la proliferación y diferenciación de células mesenquimales indiferenciadas en odontoblastos, que producirán nueva dentina. La adhesión celular está mediada por la interacción con proteínas preadsorbidas como fibronectina, vitronectina, colágeno, laminina y fibrina, provenientes de medios de cultivo, sangre y fluidos corporales o depositadas por las propias células ${ }^{44}$. La adhesión celular se ve afectada por propiedades de la superficie como la estructura química, la topografia ${ }^{45}$ y la humectabilidad ${ }^{46,47}$. Las soluciones desmineralizantes, como EDTA, aumentan la humectabilidad de la superficie de la dentina y pueden inducir una mayor adhesión celular ${ }^{47}$. El aumento de la adhesión celular puede estar relacionado con el aumento de la adhesión de la fibronectina, que es la principal proteína de adhesión y tiende a adsorberse preferentemente en superficies hidrófilas ${ }^{46}$. 
Aunque no hubo una distribución uniforme de las células de la papila apical, la adhesión celular se produjo en todos los grupos experimentales en los que los discos se trataron con soluciones desmineralizantes. La mayor humectabilidad de la superficie de la dentina, promovida por estas sustancias, explica estos resultados.

Deberían realizarse más estudios para aclarar cómo el uso de estas soluciones desmineralizantes, y ahora con los interesantes resultados obtenidos con EGTA, afectan la proliferación y diferenciación de las células de la papila apical y, por tanto, en los procesos de regeneración.

\section{Conclusiones}

El tipo de solución desmineralizante interfiere con la cantidad liberada de factores de crecimiento BMPR1 y TGFBR1, presentes en la dentina humana, y EGTA pudo inducir un aumento significativo en la expresión del receptor TGBR1.

La naturaleza química de la solución desmineralizante no fue diferente entre las soluciones.

\section{Conflicto de intereses}

Los autores declararon no tener ningún conflicto de interés personal, financiero, intelectual, económico y de interés corporativo con Universidad Central del Ecuador y los miembros de la revista Odontología.

\section{Contribución de los autores}

Paola Daniela Hidalgo Araujo, Ana Clara Fagundes Pedroni, Lais Prado Cunha, Elaine Faga Iglecias, Giulio Gavini, son responsables de la: a Concepción y diseño del trabajo; b Recolección/obtención de resultados; c Análisis e interpretación de datos; d Redacción del manuscrito; e Revisión crítica del manuscrito; f Aprobación de su versión final.

\section{Financiación}

Este trabajo fue financiado por sus autores.

\section{Referencias}

1. Bose R, Nummikoski P, Hargreaves K. A retrospective evaluation of radiographic outcomes in immature teeth with necrotic root canal systems treated with regenerative endodontic procedures. J Endod 2009;35:1343-9.

2. Rafter M. Apexification: a review. Dent Traumatol 2005;21:1-8.

3. Witherspoon D, Small J, Regan J, et al. Retrospective Analysis of Open Apex Teeth Obturated with Mineral Trioxide Aggregate. J Endod. 2008:34:1171-6.

4. Shah N, Logani A, Bhaskar U, Aggarwal V. Efficacy of revascularization to induce apexification/apexogensis in infected, nonvital, immature teeth: a pilot clinical study. J Endod. 2008 Aug;34(8):919-25.

5. Wang X, Thibodeau B, Trope M, Lin LM, Huang GT. Histologic characterization of regenerated tissues in canal space after the revitalization/revascularization procedure of immature dog teeth with apical periodontitis. J Endod. 2010 Jan;36(1):56-63.

6. Bansal R, Bansal R. Regenerative endodontics: a state of the art. Indian J Dent Res. 2011 JanFeb;22(1):122-31.

7. Zhang W, Yelick PC. Vital pulp therapy-current progress of dental pulp regeneration and revascularization. Int J Dent. 2010;2010:856087.

8. Huang GT, Sonoyama W, Liu Y, Lin H, Wang S, Shi S. The hidden treasure in apical papilla: the potential role in pulp/ dentin regeneration and bioroot engineering. J Endod. 2008 Jun;34(6):645-51.

9. Gomes-Filho JE, Duarte PC, Ervolino E, Mogami Bomfim SR, Xavier Abimussi CJ, Mota da Silva Santos $\mathrm{L}$, et al. Histologic characterization of engineered tissues in the canal space of closed- apex teeth with apical periodontitis. J Endod. 2013.

10. AAE- American Association of Endodontics. Considerations for Regenerative Procedures [citado 1 out. 2013]. Disponível em: http://www.aae.org/clinicalresources/regenerativeendodontics/considerations-for- 
regenerativeprocedures.aspx.

11. Wigler R, Kaufman AY, Lin S, et al. Revascularization: a treatment for permanent teeth with necrotic pulp and incomplete root development. J Endod 2013;39:319-26.

12. Clarkson RM, Moule AJ. Sodium hypochlorite and its use as an endodontic irrigant. Aust Dent J. 1998 Aug;43(4):250-6.

13. Gavini G, Siqueira EL, Lemos EM, Amaral KF. Substancias Químicas. In: MACHADO MEL. Endodoncia - Ciencia y Tecnologia. Caracas: AMOLCA; 2016. p. 539-577.

14. Trevino EG, Patwardhan AN, Henry MA, et al. Effect of irrigants on the survival of human stem cells of the apical papilla in a platelet-rich plasma scaffold in human root tips. J Endod 2011;37:1109-15.

15. Tziafas D, Alvanou A, Panagiotakopoulos N, Smith AJ, Lesot H, Komnenou A, Ruch JV. Induction of odontoblast-like cell differentiation in dog dental pulps after in vivo implantation of dentine matrix components. Arch Oral Biol. 1995 Oct;40(10):883-93.

16. Zhao S, Sloan AJ, Murray PE, Lumley PJ, Smith AJ. Ultrastructural localisation of TGF-beta exposure in dentine by chemical treatment. Histochem J. 2000 Aug;32(8):489-94.

17. Pang N, Seung Jong Lee, Euiseong Kim, et al. Effect of EDTA on Attachment and Differentiation of Dentária Pulp Stem Cells. J Endod. 2014 Jun;40:5.

18. Galler k, Buchalla W, Hiller K, et al. Influence of Root Canal Disinfectants on Growth Factor Release from Dentin. J Endod. 2015:41:363-8.

19. Santibañez JF, Quintanilla M, Bernabeu C. TGF- $\beta$ /TGF- $\beta$ receptor system and its role in physiological and pathological conditions. Clin Sci (Lond). 2011 Sep;121(6):233-51.

20. Cassidy N, Fahey M, Prime SS, Smith AJ. Comparative analysis of transforming growth factor-beta isoforms 1-3 in human and rabbit dentine matrices. Arch Oral Biol. 1997 Mar;42(3):219-23.

21. Toyono T, Nakashima M, Kuhara S, Akamine A. Expression of TGF-beta superfamily receptors in dental pulp. J Dent Res. 1997 Sep;76(9):1555-60

22. Sloan AJ, Smith AJ. Stimulation of the dentine-pulp complex of rat incisor teeth by transforming growth factor-beta isoforms 1-3 in vitro. Arch Oral Biol.1999 Feb;44(2):149-56.

23. Shirakawa M, Shiba H, Nakanishi K, Ogawa T, Okamoto H, Nakashima K, Noshiro M, Kato Y. Transforming growth factor-beta-1 reduces alkaline phosphatase mRNA and activity and stimulates cell proliferation in cultures of human pulp cells. J Dent Res. 1994 Sep;73(9):1509-14.

24. Shiba H, Fujita T, Doi N, Nakamura S, Nakanishi K, Takemoto T, Hino T, Noshiro M, Kawamoto T, Kurihara H, Kato Y. Differential effects of various growth factors and cytokines on the syntheses of DNA, type I collagen, laminin, fibronectin, osteonectin/secreted protein, acidic and rich in cysteine (SPARC), and alkaline phosphatase by human pulp cells in culture. J Cell Physiol. 1998 Feb;174(2):194-205.

25. Melin M, Joffre-Romeas A, Farges JC, Couble ML, Magloire H, Bleicher F. Effects of TGFbeta1 on dental pulp cells in cultured human tooth slices. J Dent Res. 2000 Sep;79(9):1689-96.

26. Kim M, Choe S. BMPs and their clinical potentials. BMB Rep. 2011 Oct;44(10):619-34.

27. Solofomalala GD, Guery M, Lesiourd A, Le Huec JC, Chauveaux D, LaVenetre O. Bone morphogenetic proteins: from their discoveries till their clinical applications. Eur J Orthop Surg Traumatol. 2007;17(6):60915.

28. Chen D, Zhao M, Mundy GR. Bone morphogenetic proteins. Growth Factors. 2004 Dec;22(4):233-41. Review. PubMed PMID: 15621726.

29. Matthews SJ. Biological activity of bone morphogenetic proteins (BMP's). Injury. 2005 Nov;36 Suppl 3:S34-7.

30. Ivica A, Deari S, Patcas R, Weber FE, Zehnder M. Transforming Growth Factor Beta 1 Distribución y Contenido en la Dentina raíz de jóvenes maduros e inmaduros premolares humanos. J Endod. 2020 
mayo;46(5):641-647.

31. Galler KM, Widbiller M, Buchalla W, Eidt A, Hiller KA, Hoffer PC, Schmalz G. EDTA conditioning of dentine promotes adhesion, migration and differentiation of dental pulp stem cells. Int Endod J. 2016 Jun;49(6):581-90.

32. Hashimoto K, Kawashima N, Ichinose S, Nara K, Noda S, Okiji T. EDTA Treatment for Sodium Hypochlorite-treated Dentin Recovers Disturbed Attachment and Induces Differentiation of Mouse Dental Papilla Cells. J Endod. 2018 Feb;44(2):256-262.

33. Serper A, Çalt S. The demineralizing effects of EDTA at different concentrations and $\mathrm{pH}$. J Endod 2002;28:501-2.

34. Sousa-Neto M, Passarinho-neto J, Carvalho-júnior J, et al. Evaluation of the Effect of EDTA, EGTA and CDTA on Dentin Adhesiveness and Microleakage with Different Root Canal Sealers. Braz Dent J (2002) 13(2): 123-128.

35. Sousa S e Silva T. Desmineralization effect of EDTA, EGTA, CDTA and citric acido n root dentin: a comparative study. Braz Oral Res 2005 19:3.

36. Calt S, Serper A. Smear layer removal by EGTA. J Endod. 2000 Aug;26(8):459-61.

37. Scelza MF, Pinheiro Daniel RLD, Santos EM, Jaeger MMM. Cytotoxic effects of $10 \%$ citric acid and EDTA-T used as root canal irrigants: an in vitro analysis. J Endod 2001;27:741-3.

38. Scelza MFZ, Teixeira AM, Scelza P. Decalcifying effect of EDTA-T, 10\% citric acid and 17\% EDTA on root canal dentin. Oral Surg Oral Med Oral Pathol Oral Radiol 2003;95:234-6.

39. Amaral KF, Rogero MM, Fock RA, Borelli P, Gavini G. Cytotoxicity analysis of EDTA and citric acid applied on murine resident macrophages culture. Int Endod J.2007 May;40(5):338-43.

40. Smith AJ, Leaver AG. Non-collagenous components of the organic matrix of rabbit incisor dentine. Arch Oral Biol. 1979;24(6):449-54.

41. Mazzoni A, Pashley DH, Tay FR, Gobbi P, Orsini G, Ruggeri A Jr, Carrilho M, Tjäderhane L, Di Lenarda R, Breschi L. Immunohistochemical identification of MMP-2 and MMP-9 in human dentin: correlative FEI-SEM/TEM analysis. J Biomed Mater Res A. 2009 Mar 1;88(3):697-703.

42. Roberts-Clark DJ, Smith AJ. Angiogenic growth factors in human dentine matrix. Arch Oral Biol. 2000 Nov;45(11):1013-6.

43. Tziafas D, Smith AJ, Lesot H. Designing new treatment strategies in vital pulp therapy. J Dent. 2000 Feb;28(2):77-92.

44. Bacakova L, Filova E, Parizek M, et al. Modulation of cell adhesion, proliferation and differentiation on materials designed for body implants. Biotechnol Adv. 2011;29: 739-67.

45. Roach P, Farrar D, Perry CC. Interpretation of protein adsorption: surface-induced conformational changes. J Am Chem Soc. 2005 Jun 8;127(22):8168-73.

46. Wei J, Igarashi T, Okumori N, Igarashi T, Maetani T, Liu B, Yoshinari M. Influence of surface wettability on competitive protein adsorption and initialattachment of osteoblasts. Biomed Mater. 2009 Aug;4(4):045002.

47. Huang X, Zhang J, Huang C, Wang Y, Pei D. Effect of intracanal dentine wettability on human dental pulp cell attachment. Int Endod J. 2012 Apr;45(4):346-53. 